\section{Assessment of neuropathy by electrophysiology of visual pathway in welding workers}

Sir,

There are reports those addresses the pattern of eye diseases among welders. ${ }^{[1]}$ Welding is one of the most intense artificial sources of invisible and visible optical radiation, near and far infrared, ultraviolet $\mathrm{A}, \mathrm{B}$ and $C$ from visible light, emitted in various degrees by the various types of welding ${ }^{[2]}$ that may cause ocular damage of different types. ${ }^{[1]}$ The electrophysiologic examination, visual evoked potentials (VEP) can objectively evaluate the toxic effects of chemicals on the central nervous system. The use of welding has increased in recent years but studies from this region remain scant. On this background this study was conducted to assess the neuropathy by electrophysiology of visual pathway in welding workers. The present study was carried out with approval from institutional ethics committee. A study was conducted from March to December 2013 on 33 welding workers. Apparently 42 healthy controls having no exposure of welding works were taken. Neuropathy was assessed by measuring VEP parameters. Pattern reversal visual evoked potential (PRVEP) for each subject was recorded with PC based 2 channels EMG-NCS-EP set, model RMS EMG EP MARK-II-2011 with Oz-Fz montage in a uniformly illuminated and noise attenuated room through checker-board stimulation via a monitor kept about $100 \mathrm{~cm}$ in front of eye.

The present study showed that among the welding workers all work regularly and $90.9 \%$ workers are from an electric arc welding workshop. Maximum number of workers uses the protection or guard (87.88\%). Comparison of mean values of latencies of wave N75, P100, and N145 of the welder's with that of the control group showed that the mean values of latencies of wave N75, P100, N145 and amplitude of waves (P100-N75) were found to be significantly more in welders in both the eyes than the control. This study provides electrophysiological evidence that the welding exposure delays the conduction processes in optical pathways as there was a significantly prolonged P100, N75 and N145 latencies and significantly reduced mean amplitude P100-N75 in welding worker. In a previous study authors reported abnormal VEP, asymmetries in inter-ocular P100 latency exceeding $6 \mathrm{~ms}$ and decreased amplitude in single tests among the welders exposed to manganese. ${ }^{[3]}$
Another study reported ocular hazards in arc welders due to ultraviolet radiation. ${ }^{[4]}$ Major limitation of the study is its small sample size. Further large-scale studies are urgently needed to assess the subclinical damage of visual pathway by electrophysiology of the optic nerve.

Joyashree Banerjee, Pranab Kumar Dey ${ }^{1}$, Anilbaran Singhamahapatra, Sayandeep Pradhan

Department of Physiology, RG Kar Medical College, Kolkata, ${ }^{1}$ Department of Paediatrics, Midnapur Medical College, Midnapur, West Bengal, India

Address for correspondence: Dr. Joyashree Banerjee, Flat No. B/6, Government Housing Estate, 82-Belgachia Road, Kolkata - 700037 , West Bengal, India. E-mail: banerjeedrjoyashree@gmail.com

\section{References}

1. Ajayi Iyiade A, Omotoye Olusola J. Pattern of eye diseases among welders in a Nigeria community. Afr Health Sci 2012;12:210-6.

2. Hinrichs JF. Safety and health project committee on radiation. Summary report. Welding Journal 1978;57:62.

3. Hałatek T, Sinczuk-Walczak H, Szymczak M, Rydzynski K. Neurological and respiratory symptoms in shipyard welders exposed to manganese. Int J Occup Med Environ Health 2005;18:265-74.

4. Brittain GP. Retinal burns caused by exposure to MIG-welding arcs: Report of two cases. Br J Ophthalmol 1988;72:570-5.

\begin{tabular}{|l|l|}
\hline \multicolumn{2}{|c|}{ Access this article online } \\
\hline Quick Response Code: & Website: \\
\hline & www.ruralneuropractice.com \\
\cline { 2 - 2 } & \\
\hline
\end{tabular}

